\title{
The influence of personal networks and social support on study attainment of students in university education
}

\author{
Lilian Eggens $\cdot$ M. P. C. van der Werf · R. J. Bosker
}

Published online: 3 July 2007

(C) Springer Science+Business Media B.V. 2007

\begin{abstract}
In this paper, the influence of personal networks and social support on study attainment of students in university education is examined. Furthermore, the paper aimed at clarifying the possible mediating role of achievement motivation, time spent on studying and working, procrastination and self-esteem. The study is a follow-up of the ' 89 cohort study, but is restricted to those students who have transferred to university education after finishing secondary education. The students have been approached with a questionnaire in 2004. Multinomial logistic regression shows that social support has no effect on study attainment, but that personal networks do have an effect on attainment. The relationship between social support and personal networks on the one hand and study progress on the other hand is not mediated by the before mentioned variables.
\end{abstract}

Keywords Personal network - Social support - University · Higher education · Attainment $\cdot$ Student $\cdot$ Achievement motivation $\cdot$ Self-esteem $\cdot$ Procrastination

Students who transfer to higher education face a number of changes in their personal and academic environment. The transition from secondary education to higher education not only calls for academic adjustment, but also includes different social demands. Students need to develop new or increased capacity for self-regulation and must learn to cope with the time pressure that is inherent in going to college. Moreover, students must integrate into a new social environment. They leave their parental house, most of their former classmates and teachers and they meet new friends, housemates and classmates. Existing supportive relationships may change or even disappear, and new supportive connections can be formed. The extent to which students succeed in integrating into this new environment and also the amount of social support received from network members possibly determines part of their academic success or failure.

L. Eggens $(\varangle) \cdot$ M. P. C. van der Werf · R. J. Bosker Groningen Institute for Educational Research, University of Groningen, Grote Rozenstraat 3, 9712 TG Groningen, The Netherlands e-mail: 1.eggens@rug.nl 
Most models for explaining academic performance in higher education are based on the interaction model developed by Spady (1970, 1971), further elaborated on by Tinto (1975). Based on these and other models, a wide range of possible determinants of academic performance has been described and tested, which can roughly be divided into contextrelated factors like curricular characteristics and assessment procedures, and studentrelated factors like gender, motivation and learning styles. These variables are mainly academic and/or personal determinants though, leaving the students' social environment out of consideration.

This study examined the influence of personal networks and social support on academic attainment of students in university education. The impact of students' social support and personal network was studied together with the influence of achievement motivation, study related well-being, study behavior and self-esteem. The relative contributions of these variables and their mutual relationships were examined, controlling for SES, gender, prior achievement and recommendation (the advice of the primary school on the level of secondary education a student should transfer to).

\section{Theoretical background}

Predictors of academic attainment in higher education ${ }^{1}$

The most straightforward determinants of student performance in higher education are the results that students previously attained. Students who perform well in secondary education usually continue this high performance (Bruinsma 2003; Jansen 2004; McKenzie and Schweitzer 2001; Murtaugh et al. 1999; Pustjens et al. 2004; Smith and Naylor 2001; Szafran 2001; Zeegers 2004).

Student age is also a significant predictor of study success. Generally, younger students perform better than older students (Bruinsma 2003; Jansen 2004; Murtaugh et al. 1999; Van den Berg and Hofman 2005), but in some studies this relationship differed between men and women or between various study subjects (Richardson and Woodley 2003; Smith and Naylor 2001). (NP) In addition to age, also gender plays an important role in predicting performance. In general, women are more successful than men; they attain higher grades, finish their study faster and show less retention than men (Bruinsma 2003; Jansen 2004; Richardson and Woodley 2003; Smith and Naylor 2001).

The socioeconomic status (SES) of the students also determines student attainment. The more 'advantaged' student's home background, the better their academic performance (Pustjens et al. 2004; Robbins et al. 2004; Smith and Naylor 2001; Smith and Naylor 2005). In some studies though, SES did not have a significant effect (Van den Berg 2002; Van den Berg and Hofman 2005).

Achievement motivation is among the most predictive constructs. The higher the students are motivated, the higher their academic performance (Archer et al. 1999; Eppler et al. 2000; Hofman and Van den Berg 2004; McKenzie et al. 2004; Robbins et al. 2004; Zeegers 2004).

Although detrimental effects of procrastination are often assumed, this assumption is not always supported by the data. In some studies, procrastination had an adverse effect on

1 This paragraph is not a complete overview of determinants of study performance, but is restricted to the variables that are relevant to this study. 
academic performance (Fritzsche et al. 2003; Jackson et al. 2003; Robbins et al. 2004; Rothblum et al. 1986; Tice and Baumeister 1997; Wesley 1994), but in other studies this effect did not occur (Beck et al. 2001; Cassady and Johnson 2002; Pychyl et al. 2001). An explanation for these inconsistencies might be that most measures of student performance in these studies concerned incidental test scores or grade point average's (GPA), while there might be a much larger cumulative influence of procrastination on long term study progress.

Academic performance in higher education also depends on the amount of time students spend on studying and-opposing — the time students spend on work, because it interferes with time spend on studying (Curtis and Shani 2002; Van den Berg 2002; Van den Berg and Hofman 2005). (NP) Finally, the influence of self-esteem on performance could not be confirmed in a number of studies (Clifton et al. 2004; Lane et al. 2004; Robbins et al. 2004), but some evidence for the effect of self-esteem was found by Levitt et al. (1994), who found self-concept to significantly predict GPA of students in secondary education.

\section{Personal networks}

Although a relationship between (characteristics of) personal networks and academic performance has been theorized, empirical evidence is scarce. One important exception is the influence of peer groups on student performance, which has been tested in several studies, for instance for adolescents by Ryan (2000, 2001), for children in secondary schools by Davies and Kandel (1981) and Lubbers (2004), and for students in higher education and/or university by Robbins et al. (2004). Being integrated in a personal network may facilitate student performance, but certain network characteristics may hamper educational outcomes as well. Hays and Oxley (1986) found the number of fellow students in the network of college freshman the variable most strongly related to students adaptation. However, they also stated that integration in a personal network of family members, neighbors and/or colleagues may involve norms and demands that compete with the role requirements of a successful student.

The influence of personal networks on performance can be direct as well as indirect. One of the possible mediating factors between personal networks and performance is achievement motivation. Network members can motivate students' desire to achieve academically by providing them with standards and expectations for performance. The quality of these relationships can also influence the likelihood that these goals will be pursued (Ryan 2000, 2001; Wentzel 1999; Wentzel et al. 2004).

Another possible mediating factor is self-esteem or self-worth. Personal networks, and in particular friendships within these networks, possibly enhance student's self-esteem, which in turn might positively influence student performance. Keefe and Berndt (1996) and Hay and Ashman (2003) have found evidence for this relationship for respectively seventh and eighth grade students and tenth grade students.

The quality and quantity of students' relationships, the structure of their personal networks and their influence on academic performance have mainly been studied within students' classroom or college environment. Particularly the college peer group, but also teacher(s) have been reported as an important factor in the socialization and enhancement of student's motivation and academic performance in different tracks of education and among different age groups (Berndt et al. 1990; Berndt and Keefe 1995; Davies and Kandel 1981; Keefe and Berndt 1996; Ryan 2000, 2001; Wentzel 1998; Wentzel et al. 2004). This emphasis on peer networks leaves the students' contacts outside class or 
college out of consideration, in spite of the earlier described theoretical considerations of Wentzel, Cohen et al. and Levitt et al. about the influence of family members, friends and romantic partners.

\section{Social support}

Lakey and Cohen (2000) stated that support is strongly associated with self-evaluation and that perceived support promotes self-esteem and thereby promotes well-being. Evidence for this perspective applied to the relationship between support and academic performance was found among undergraduate students by Cutrona et al. (1994) and among students in grades 1-2, 4-5 and 8-9 by Levitt et al. (1994). Cutrona et al. found parental support to predict academic performance in a direct way, but this prediction was the result of one single component of parental support: reassurance of worth. This suggests that social support may enhance students' self-esteem and thereby indirectly influences academic performance. This indirect relationship between social support and academic performance through self-esteem was also found by Levitt et al. Cutrona et al. furthermore stated that support from peers and romantic partners, but particularly support from parents would enhance well-being and therefore would add to the explained variance in academic performance. Parental support is supposed to be most influential, because a lifetime of parental support contributes to the development of high self-worth and self-efficacy, and allows the acquisition of skills and self-confidence to master new situations and cope effectively with challenges (Cutrona et al. 1994; DuBois et al. 1994; Dubow et al. 1991; Levitt et al. 1994).

Support from parents and family members might decrease, as students get older. Support provided by peers becomes more and more important in the life of adolescents, as friends and partners often are in more frequent contact with college students than are parents. Although research findings show that support from parents better predicts academic performance than support from friends, other family and/or other network members, support from friends and peers is still found to significantly predict academic performance (Levitt et al. 1994; Wall et al. 1999).

In addition to the source of social support, also the type of support is important for students' well-being and study behavior. Several types of support have been defined in previous studies (Cohen et al. 1985; Davis et al. 1998; Malecki and Demaray 2005), e.g. emotional support, instrumental support and companionship, and these different types of support are found to influence children's as well as college students' adjustment and performance (Davis et al. 1998; Malecki and Demaray 2005; Richman et al. 1998). Malecki and Demaray (2005) for instance found emotional support from teachers to be a significant and individual predictor of social skills and academic competence.

Finally, social support can influence students' performance through student motivation. Perceived social and emotional support from parents, other family members and from peers has been found positively related to motivational outcomes of undergraduate students (Kennedy et al. 1988; Wentzel 1998; Wentzel 1999). Support from parents, peers and others might play a role in buffering the influence of stress on motivation by means of enhancing well-being (Wentzel 1999). Social support also might influence the desire to achieve academically by stimulating students to adopt socially valued goals and objectives (Ryan 2000, 2001; Wentzel 1998).

Social support can influence academic performance through the enhancement of well-being, self-esteem and motivation, but the total level of support is also found to be a 
significant and direct predictor of academic performance among college students (DeBerard et al. 2004; Dubow et al. 1991; Robbins et al. 2004).

Although social support can only occur within personal networks, it is important to distinguish between these two concepts. Social support involves the perceived availability or actual provision of emotional, informational, or instrumental resources in response to the perception that others are in need of such aid. The other conceptpersonal networks-focuses on participation in one or more distinct social groups without the intention to exchange help or support (Cohen et al. 2001). Research on personal network is mainly aimed at the structure of human connections, while research on social support is mainly concerned about the content of human connections (Pescosolido and Levy 2002).

In this study, personal networks and social support are considered and measured as two different, but interrelated concepts. Only personal network members can provide social support, and the size and diversity of the network will influence the amount and type of support. The effect of social support therefore is partly an effect of personal network characteristics, or as Faber and Wasserman (2002) stated, social support is one possible type of relational variable that can be measured for actors in a personal network.

In conclusion, the influence of personal networks and social support on academic performance can be both direct and indirect and the link between personal networks and social support and academic performance can be mediated by self-esteem, well-being and achievement motivation.

Although the mediating role of achievement motivation between personal networks and academic outcomes has repeatedly been hypothesized and tested, there has been very little attention given to the influence of network members on other facets of studying and learning. As network members socialize students' behavior in the academic environment, it can be argued that this influence is not only restricted to achievement motivation, but might also influence other behaviors such as procrastination or time spent on studying and working.

This study examined the relationship between personal networks and social support and academic attainment, and the mediating role of motivation, study related well-being, procrastination, time spent studying and working and finally self-esteem. Mediation requires that social support and personal networks have a direct effect on student attainment as well as on the mediators, that the mediators have an effect on students' attainment and that the direct effect of support and networks on students' attainment decreases or disappears when the mediating variables are entered into the model.

\section{Method}

Subjects and procedure

In 1989, a longitudinal study was started in the Netherlands among 18.500 students in grade 7 (age 12/13) in 381 schools for secondary education. In the first year of the cohort, school administrations provided information about the gender and ethnicity of the students, and the students' parents filled in a questionnaire. The students were tested in grades 7, 9 and 11. From these tests, data are available about students' previous achievement. Furthermore, administrations of the schools for secondary education provided data about track placement and grade promotion of the students each year. 
This study is a follow-up, but it is restricted to those students $(N=5098)$ in the cohort who finished senior general secondary education (SGSE) and/or pre-university education (PUE) and have transferred to university education (UE). The students were approached again in 2004 with a questionnaire, measuring study attainment, personal networks, social support and self-esteem. A repeated measurement of study behavior, achievement motivation and study related well-being was also included.

Of the 5098 students who were approached, 1451 students completed and sent back the questionnaire; the response therefore was $28 \%$. To check the representativeness of the response group, the differences between the responding and the non-responding students with respect to level of secondary education, gender and SES were tested with Pearson's $\chi^{2}$ test, and the differences concerning scores on the entry test, achievement motivation and study related well-being were tested with an independent $t$-test. Only the differences in prior educational level, gender and SES were significant and relatively large. These variables were included as covariates in the analyses and thus were controlled for.

\section{Measures}

\section{Predictor variables}

Personal networks. Compositional information was collected for the personal networks of the respondents. To obtain this information, an extended version of the network delineation instrument constructed by Straits (2000) was used. The students were asked to write down five persons they discussed important matters with during the last/preceding year of their study. For each of these network members, questions were asked about (a) the frequency of contact, (b) the kind of relationship, for instance parent or friend (12 categories in total, multiple answers possible) and (c) the subjects being discussed with the network members, for instance school or money (13 categories in total, multiple answers possible). For each of these variables, the total score was divided by the number of network members to create a mean score. This mean score indicates the mean amount of contact with the network members, the mean number of roles with the network members and the mean number of subjects discussed with the network members. Finally, the network density was indicated; the network members were placed in a diagram and the students were asked to draw lines between the network members who regularly had contact with each other. The more lines were drawn between the network members, the more dense the network.

Social support. The 12 item version of Cohen's interpersonal support evaluation list (ISEL) (Cohen et al. 1985) was fitted for gathering information about the source and type of social support within the personal network. The ISEL contains the subscales companionship, emotional support and instrumental support, each consisting of four items. In addition to the type of support, also the source of support was determined. Four sources of support were distinguished: partners, parents, peers and family members. A combination was made with the source of support and the type of support to create twelve yes/no variables, indicating whether students received a certain type of support from a certain source of support, for instance instrumental support from parents or emotional support from peers. 


\section{Mediating variables}

Achievement motivation. In the first and third cohort year, a revised version of the achievement motivation scale of Hermans (1980) was used. This scale was adapted for use in higher education and consisted of two subscales: achievement motivation (16 items) and study related well-being ( 9 items). The reliability of the achievement motivation subscale was .82 (coefficient alpha) and of the study related well-being subscale .71 (coefficient alpha).

Time spent studying and working. The number of hours per week students on average spent studying and working during the last year of their study was also included in the questionnaire.

Procrastination. Procrastination was measured using the Academic Procrastination State Inventory (APSI) of Schouwenburg (1994). The APSI consists of 15 items with a reliability of .91 (coefficient alpha).

Self-esteem. For measuring general self-esteem the widely used Rosenberg Self-Esteem Scale (Greenberger et al. 2003; Rosenberg 1965) was translated into Dutch. The scale consists of five positive and five negative formulated items. The original four-point Likert scale was extended to five-points to make the scale more consistent with the other scales in the questionnaire. The reliability of the RSES was .89 (coefficient alpha).

\section{Control variables}

The control variables were gender, SES, prior achievement, recommendation, level of secondary education, academic discipline ${ }^{2}$ in higher education and the age of the students at the moment they entered higher education. Information about gender, recommendation and prior achievement was provided by the schools for secondary education. Recommendation refers to the advice that schools for primary education give about which level of secondary education the pupil should transfer to.

The measurement of prior achievement contains two components. In the first year of secondary education, tests were taken on arithmetic, Dutch language and information processing. In the third year of secondary education, tests were taken on mathematics and text comprehension. SES was measured by the parents' questionnaire and is defined as a combination of the educational level of both parents. Information concerning the level of secondary education and the entry-age in higher education was gathered in the 2004 questionnaire.

\section{Dependent variable}

The students were asked whether they had attained a diploma and if so, the length of their study. Because there was no information on whether the real study time deviated from the nominal study time (in other words, whether students were delayed or not) an alternative measurement of student attainment had to be created.

\footnotetext{
2 The academic disciplines in higher education in the Netherlands are generally ordered in three categories: alpha, beta and gamma studies. The alpha studies consist in general of philology, literature, history, law and theology. The beta studies are the science studies, mathematics, medical sciences etcetera and the gamma studies are the humane sciences like psychology, sociology, social work, sports education, teacher education etcetera.
} 
For each academic discipline the mean study length and standard deviation were calculated. Subsequently, three groups of students were formed within each academic discipline and within each level of education: a group of students who attained their diploma with delay (mean plus $0.5 \mathrm{sd}$ and above), a group of students who attained their diploma in the nominal time (between mean plus and minus $0.5 \mathrm{sd}$ ) and a group of students who attained their diploma in less than the nominal time (mean minus $0.5 \mathrm{sd}$ and below). Finally, the last group was a group of students who did not attain a diploma.

\section{Method of analysis}

Following the research questions, the analyses were performed in four steps. First, the support variables and the network variables were used to predict attainment. Because social support takes place in social networks, the support variables were entered first into the model (model A), followed by the network variables (model B). Next, attainment was predicted by the study variables and self-esteem (model C). Subsequently, the support variables and network characteristics were used to predict the study variables and selfesteem (model D). To explore the mediating role of the study variables and self-esteem, a complete model (model E) was estimated, and this complete model was compared with model B.

Since student attainment is a nominal variable, logistic regression was the most appropriate analysis to use for models A, B and C, and for model E. Multinomial logistic regression was conducted because the parallel regression assumption was violated when performing an ordered logistic regression analyses. In logistic regression, the category with the highest value is the category against which the other categories are contrasted. In these analyses, the category nominal diploma attainment served as the reference category.

The significance of the individual parameter estimates was tested using the Wald statistic and its corresponding probability level. The model fit was tested with the model chi square test, which tests the significance of the difference between the likelihood ratio of the model in which the predictors are included minus the likelihood ratio for a model with only an intercept or another model.

In model $\mathrm{D}$, the study variables (motivation, study related well-being, procrastination and time spent studying and working) and self-esteem were predicted with the network and support variables, using stepwise linear regression analysis. In step 1, the control variables were entered into the model, followed by the support variables in step 2 and the network variables in step 3 .

\section{Results}

The influence of social support and network characteristics on attainment

In the empty model (not in table), the probability of attaining a diploma in the nominal amount of time is estimated as $1 /\left(1+\mathrm{e}^{-0.179}+\mathrm{e}^{-0.398}+\mathrm{e}^{-0.283}\right)=0.307$, the probability of delayed diploma attainment is $\mathrm{e}^{-0.398} /\left(1+\mathrm{e}^{-0.179}+\mathrm{e}^{-0.398}+\mathrm{e}^{-0.283}\right)=0.206$, the probability of accelerated diploma attainment is $\mathrm{e}^{-0.283} /\left(1+\mathrm{e}^{-0.179}+\mathrm{e}^{-0.398}+\mathrm{e}^{-0.283}\right)=0.231$ and the probability of not attaining a diploma is $\mathrm{e}^{-0.179} /\left(1+\mathrm{e}^{-0.179}+\mathrm{e}^{-0.398}+\mathrm{e}^{-0.283}\right)=0.256$. 
In the first step of the analysis, the control variables are added to the empty model. This significantly improves the model fit $\left(\chi^{2}=65.652, d f=30, p<.000\right)$. Model A contains the control variables together with the support variables (see Appendix Table 1).

Including the support variables does not result in a significantly better model fit $\left(\chi^{2}=32.659, d f=30, \mathrm{~ns}\right)$. The results show that not attaining a diploma is predicted by companionship provided by partners. Having companionship from partners decreases the odds of not attaining a diploma. None of the support variables have an effect on either delayed or accelerated diploma attainment.

Adding the network variables to the model (Model B, see Appendix Table 1), improves the model fit significantly $\left(\chi^{2}=34.671, d f=24, p<.10\right)$. Not attaining a diploma is predicted by the network density. One unit increase in the network density decreases the odds of not attaining a diploma with about $100\left(\mathrm{e}^{-1.468}-1\right)=77 \%$. The effect of companionship provided by partners decreases slightly but is still significant when the network variables are included in the model.

Delayed diploma attainment is predicted by the number of network members and the average age of the network members. One unit increase in the number of network members decreases the odds of delayed diploma attainment with $100\left(\mathrm{e}^{-0.542}-1\right)=42 \%$. The average age of the network members has a positive effect on delayed diploma attainment: one unit increase in the average age increases the odds of delayed diploma attainment with about $100\left(\mathrm{e}^{0.109}-1\right)=12 \%$. Adding the network variables to the model resulted in a significant effect of instrumental support provided by peers. The odds of students with instrumental support from peers on delayed diploma attainment are $\mathrm{e}^{1.552}=4.7$ times the odds of students without this support. Finally, none of the network variables has a significant effect on accelerated diploma attainment.

The influence of the study variables and self-esteem on attainment

In this model, attainment is predicted by the study variables and self-esteem together with the control variables. This significantly improves the model fit compared to the model containing only the control variables $\left(\chi^{2}=43.778, d f=18, p<.001\right)$. As can be seen in Table 2 in the Appendix, none of the study variables have a significant effect on delayed diploma attainment. Not attaining a diploma is predicted by the amount of time students spent working. An increase of one hour spent working increases the odds of not attaining a diploma with $100\left(\mathrm{e}^{0.033}-1\right)=3.4 \%$.

Both procrastination and self-esteem have a significant negative effect on accelerated diploma attainment. One unit increase of procrastination decreases the odds of accelerated diploma attainment with $100\left(\mathrm{e}^{-0.897}-1\right)=59 \%$. One unit increase in self-esteem decreases the odds of accelerated diploma attainment with $100\left(\mathrm{e}^{-0.446}-1\right)=36 \%$.

The influence of social support and network characteristics on the study variables

\section{Achievement motivation}

The control variables together explain almost $9 \%$ of the variance in achievement motivation. Adding the support variables to the model increases the percentage explained variance to $11 \%$ and the network variables add another $1 \%$. The overall model fit is 
significant for all models (see Appendix Table 3). Table 4 in the Appendix shows that achievement motivation is predicted by instrumental support from family members.

\section{Study related well-being}

Almost $8 \%$ of the variance in study related well-being is explained by the control variables. The support variables add another $4 \%$ to the percentage explained variance and the network variables add $2 \%$. The model fit is significant for all models (see Appendix Table 3 ), and as can be seen in Table 4 in the Appendix there is a negative and significant relationship between study related well-being and instrumental support from family members and the network density.

\section{Procrastination}

The control variables explain 5\% of the variance in procrastination, and adding the support variables increases the percentage explained variance to $7 \%$. Finally, the network variables add $1 \%$ explained variance to the model. As can be seen in Table 3 in the Appendix, only the first and the second model fit the data significantly. Emotional support from parents has a negative significant effect on procrastination (see Appendix Table 4).

\section{Hours studying}

Together, the control variables explain $4 \%$ of the variance in the number of hours students spent working. The support variables and the network variables add $3 \%$ respectively $1 \%$ to the percentage explained variance. None of the three models fit the data significantly, as can be seen in Table 3 in the Appendix. The results in Appendix Table 4 shows that companionship from partners and instrumental support from family have a significant negative effect on the amount of time students spent studying.

\section{Hours working}

Almost $8 \%$ of the variance in the amount of time students spent working is explained by the control variables, and the support variables and the network variables explain an additive $1.5 \%$ and $2.4 \%$. All three model fits are significant (see Appendix Table 3), but Table 4 in Appendix shows that none of the support variables and none of the network variables have a significant effect on time spent working.

\section{Self-esteem}

Finally, the variance in self-esteem is explained for $6 \%$ by the control variables. Adding the support variables increases the percentage explained variance to $8 \%$ and the network variables add $3 \%$ explained variance. All three models fit significant (see Appendix Table 3 ) and the results show that self-esteem increases when the number of roles increases.

The complete model

In model E, all variables are added to the model to explore the mediating role of the study variables and self-esteem. Table 5 in the Appendix shows the parameter estimates of the 
complete model. Compared to model B (Table 1 in the Appendix), the model fit of model E is significantly better $\left(\chi^{2}=39.16, d f=18, p<.01\right)$.

When including the study variables and self-esteem to complete the model, the effect of companionship from partners on not attaining a diploma increases. Furthermore, the effect of the educational level of the network on not attaining a diploma becomes significant, but the effect of the network density becomes non-significant.

The results also show changes in the effects of the support variables and the network variables on delayed diploma attainment. The effect of companionship from partners becomes significant, but the effect of instrumental support from peers becomes nonsignificant. The effect of the number of roles and the average age of the network members on delayed diploma attainment increase slightly.

In model B as well as model E, none of the support variables and none of the network variables significantly affect accelerated diploma attainment. There are differences between the effects of the study variables between both models though. The effect of procrastination on accelerated diploma attainment decreases, and the effect of self-esteem disappears.

To compare the relative contribution of the individual parameters the variables were standardized. Companionship from partners is the strongest predictor of not attaining a diploma, followed by respectively entry age, educational level of the network and the amount of time students spent studying. Delayed diploma is predicted most strongly by companionship from partners, followed by the average age of the network members and the number of network members. Finally, accelerated diploma attainment is only predicted by procrastination.

\section{Conclusion and discussion}

The first research question of this study aimed at explaining the impact of social support and personal networks on attainment in higher education. In contrast to findings of for instance DeBerard et al. (2004) and Robbins et al. (2004), including the support variables in the model did not improve the prediction of attainment. The model fit for predicting attainment significantly improved when the network variables were included in the model. The number of network members, the average age of the network members and the network density significantly predicted attainment. The more network members a student has, the lower the odds on delayed diploma attainment, but when the average age of the network members increases the odds on delayed diploma attainment also increase. Finally, a high network density prevents students from not attaining a diploma. Apparently, a dense network prevents students from less preferable study outcomes. This supported theoretical considerations of for instance Brisette et al. (2000), who stated that network density promotes the flow of support within the network. Possibly, a dense network also functions by means of social control and peer pressure, inciting students to behave in a socially desirable way (Berkman 1984).

Although social support only occurs within social networks (Cohen et al. 2001; Faber and Wasserman 2002; Pescosolido and Levy 2002), including the network variables in the model containing the support variables did not decrease the parameter estimates of the support variables. Therefore, it can be concluded that the network characteristics as measured in this study did not explain the amount, type and source of support provided by the network members. 
The second research question aimed at the mediating role of the study variables and self-esteem. Although there were some effects of the support and network variables on some of the study variables and self-esteem, these variables did not have an effect on attainment. Therefore, the study variables and self-esteem did not play a mediating role between social support and social networks on the one hand and attainment on the other hand. This is inconsistent with studies of for instance Cutrona et al. (1994) and Levitt et al. (1994) who found the relationship between support and students' performance to be mediated by self-esteem, and with studies of Wentzel (1998) and of Ryan (2000, 2001) who found the effect of support and characteristics of personal networks on performance to be mediated by motivation.

Although the study variables and self-esteem did not play a mediating role, the effects of personal networks and social support on students' study behavior and self-esteem are still relevant. The findings showed that personal networks influence students' behavior, possibly by means of peer pressure and social control, but also by providing students with information on how to behave and on what goals to achieve. Finally, personal networks can function as a safety net that helps students to cope with stress and difficulties during their study. Further research is necessary to explore and explain the pathways through which personal networks and social support effect the behavior of students in higher education.

Finally, the relative influence of all variables was explored in the third research question. Companionship from a partner prevented students from delayed diploma attainment and from not attaining a diploma. Support from parents and peers in this study did not have an effect on attainment. This is inconsistent with previous research findings (DeBerard et al. 2004; Dubow et al. 1991; Robbins et al. 2004), but possibly the general level of support from these sources was too high to make a distinction between the different groups of students.

The average educational level of the network members increased the odds on not attaining a diploma. An explanation for this can be found in the theory on social comparison. Students compare their performance with others who are important to them, and in general it is assumed that this comparison can motivate students to perform on a higher level. However, social comparison can also enhance fear of failure and reduce effort and motivation if the discrepancy between the performance of the student and the performance of the comparison other is too high.

Consistent with previous research (Beck et al. 2001; Brownlow and Reasinger 2001; Tice and Baumeister 1997), procrastination reduced the odds on accelerated diploma attainment. However, study delay was not predicted by procrastination. Not attaining a diploma was predicted by the amount of time students spent working, which is also consistent with previous studies (Curtis and Shani 2002; Van den Berg 2002; Van den Berg and Hofman 2005).

Further research is necessary to explain why personal networks have an effect on students' attainment. What processes and characteristics are responsible for this relationship? And is it possible to determine specific network typologies that are beneficial for attainment in higher education?

Acknowledgements This study was sponsored by the Dutch Science Foundation (NWO), grant number 015-001-031. 


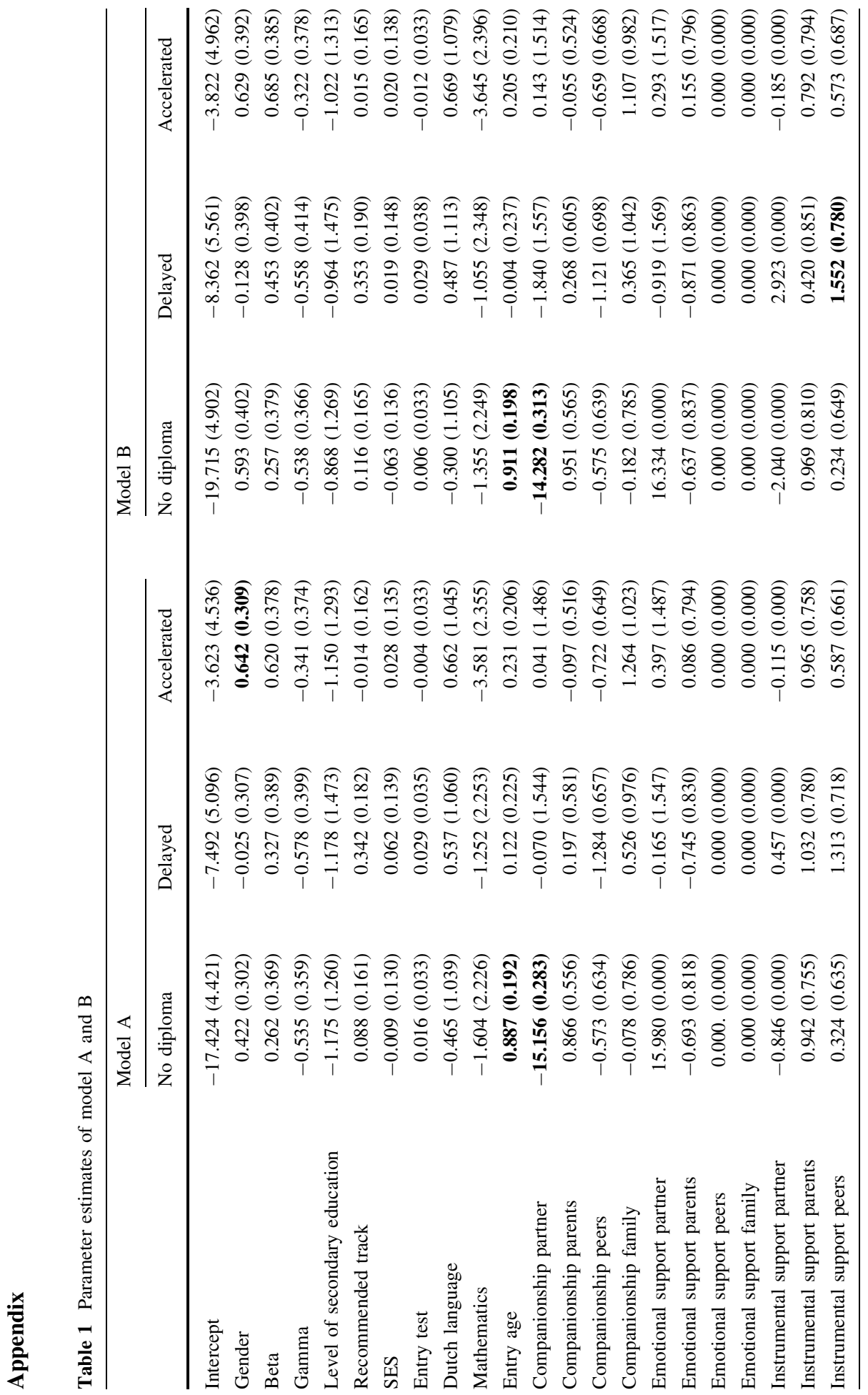




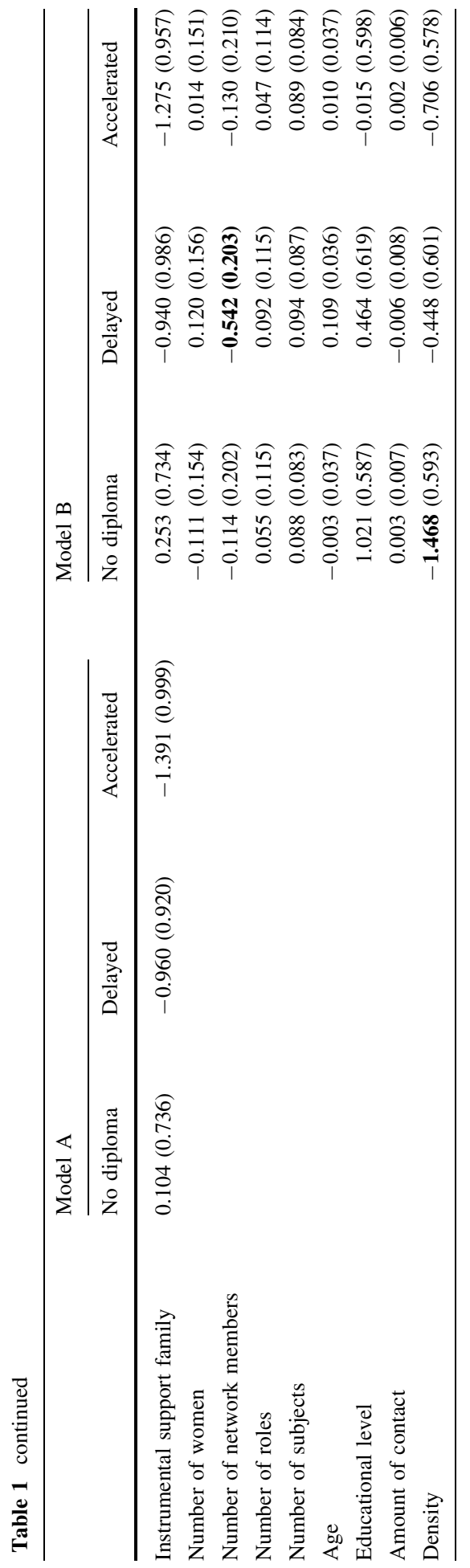


Table 2 Parameter estimates model C

\begin{tabular}{|c|c|c|c|}
\hline & No diploma & Delayed & Accelerated \\
\hline Intercept & $-12.859(4.856)$ & $-2.304(5.507)$ & $-0.344(5.081)$ \\
\hline Gender & $0.398(0.304)$ & $0.122(0.311)$ & $0.544(0.313)$ \\
\hline Beta & $0.562(0.381)$ & $0.746(0.400)$ & $0.523(0.395)$ \\
\hline Gamma & $-0.365(0.361)$ & $-0.348(0.398)$ & $-0.317(0.374)$ \\
\hline Level of secondary education & $-1.214(1.252)$ & $-1.054(1.515)$ & $-1.196(1.287)$ \\
\hline Recommended track & $0.053(0.159)$ & $0.321(0.180)$ & $-0.016(0.160)$ \\
\hline SES & $-0.008(0.129)$ & $0.029(0.138)$ & $0.030(0.133)$ \\
\hline Entry test & $0.008(0.033)$ & $0.024(0.035)$ & $-0.001(0.033)$ \\
\hline Dutch language & $0.057(1.055)$ & $0.811(1.086)$ & $0.691(1.051)$ \\
\hline Mathematics & $-1.641(2.208)$ & $-1.524(2.141)$ & $-3.075(2.335)$ \\
\hline Entry age & $0.801(0.188)$ & $0.038(0.218)$ & $0.201(0.203)$ \\
\hline Achievement motivation & $-0.376(0.491)$ & $-0.498(0.509)$ & $0.037(0.506)$ \\
\hline Study related well-being & $0.160(0.381)$ & $-0.247(0.391)$ & $0.275(0.416)$ \\
\hline Procrastination & $-0.048(0.283)$ & $0.136(0.288)$ & $-0.897(0.328)$ \\
\hline Hours spent studying & $-0.013(0.009)$ & $-0.001(0.010)$ & $0.002(0.010)$ \\
\hline Hours spent working & $0.033(0.015)$ & $0.020(0.016)$ & $0.006(0.017)$ \\
\hline Self-esteem & $-0.380(0.220)$ & $-0.408(0.224)$ & $-0.446(0.220)$ \\
\hline
\end{tabular}

Table 3 Model information for model D

\begin{tabular}{|c|c|c|c|c|}
\hline & $R^{2}$ & $F$ & $d f$ & $p$ \\
\hline \multicolumn{5}{|c|}{ Achievement motivation } \\
\hline Step 1 & .088 & 4.128 & 10,426 & .000 \\
\hline Step 2 & .114 & 2.689 & 20,416 & .000 \\
\hline Step 3 & .124 & 2.063 & 28,408 & .001 \\
\hline \multicolumn{5}{|c|}{ Study related well-being } \\
\hline Step 1 & .078 & 3.617 & 10,426 & .000 \\
\hline Step 2 & .115 & 2.696 & 20,416 & .000 \\
\hline Step 3 & .134 & 2.258 & 28,408 & .001 \\
\hline \multicolumn{5}{|c|}{ Procrastination } \\
\hline Step 1 & .054 & 2.442 & 10,426 & .008 \\
\hline Step 2 & .072 & 1.607 & 20,416 & .048 \\
\hline Step 3 & .077 & 1.209 & 28,408 & .216 \\
\hline \multicolumn{5}{|c|}{ Hours studying } \\
\hline Step 1 & .036 & 1.570 & 10,426 & .113 \\
\hline Step 2 & .063 & 1.410 & 20,416 & .113 \\
\hline Step 3 & .075 & 1.182 & 28,408 & .242 \\
\hline \multicolumn{5}{|c|}{ Hours working } \\
\hline Step 1 & .075 & 3.446 & 10,426 & .000 \\
\hline Step 2 & .090 & 2.049 & 20,416 & .005 \\
\hline Step 3 & .114 & 1.867 & 28,408 & .005 \\
\hline \multicolumn{5}{|c|}{ Self-esteem } \\
\hline Step 1 & .061 & 2.755 & 10,426 & .003 \\
\hline Step 2 & .084 & 1.898 & 20,416 & .011 \\
\hline Step 3 & .111 & 1.820 & 28,408 & .007 \\
\hline
\end{tabular}




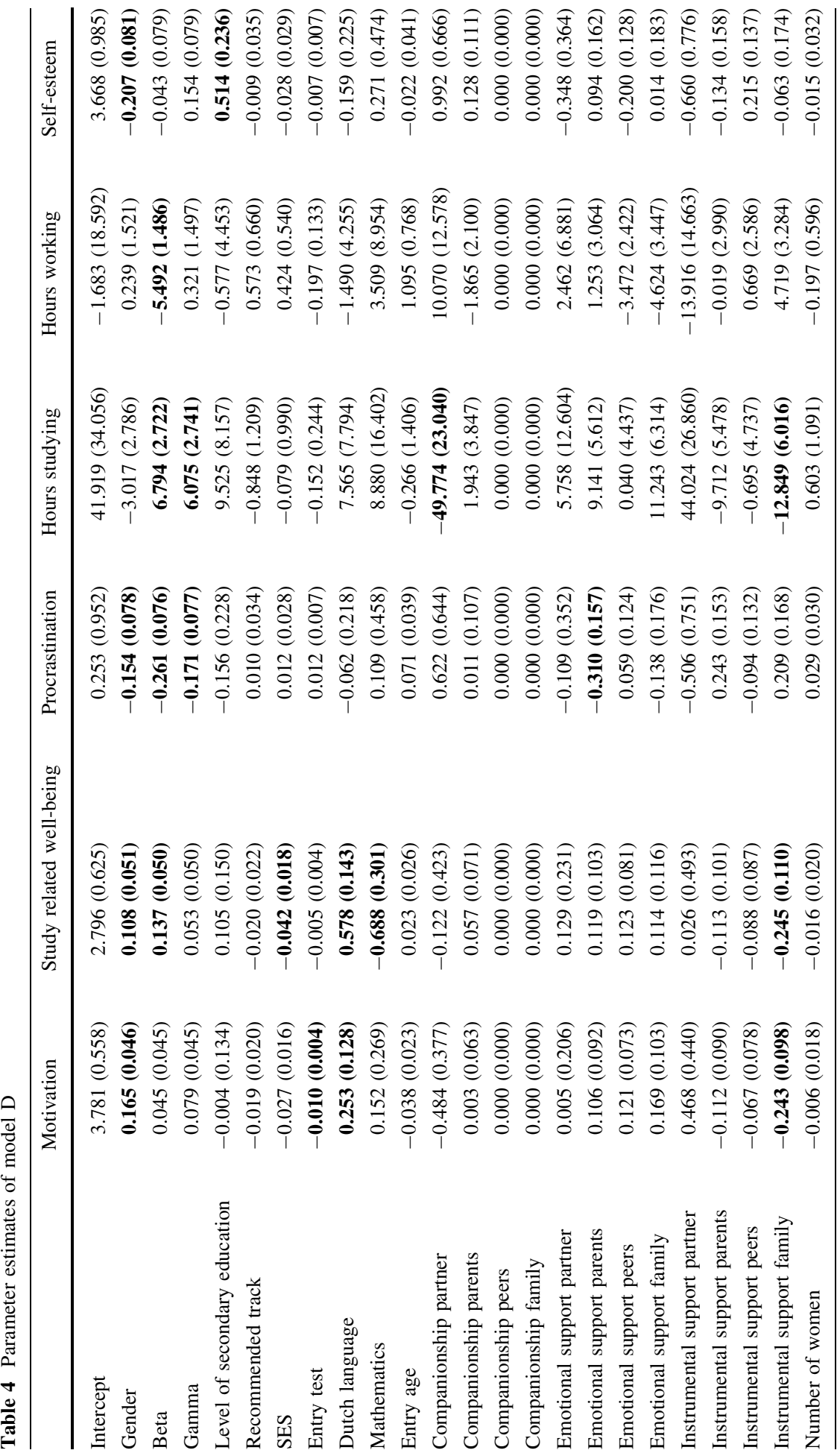




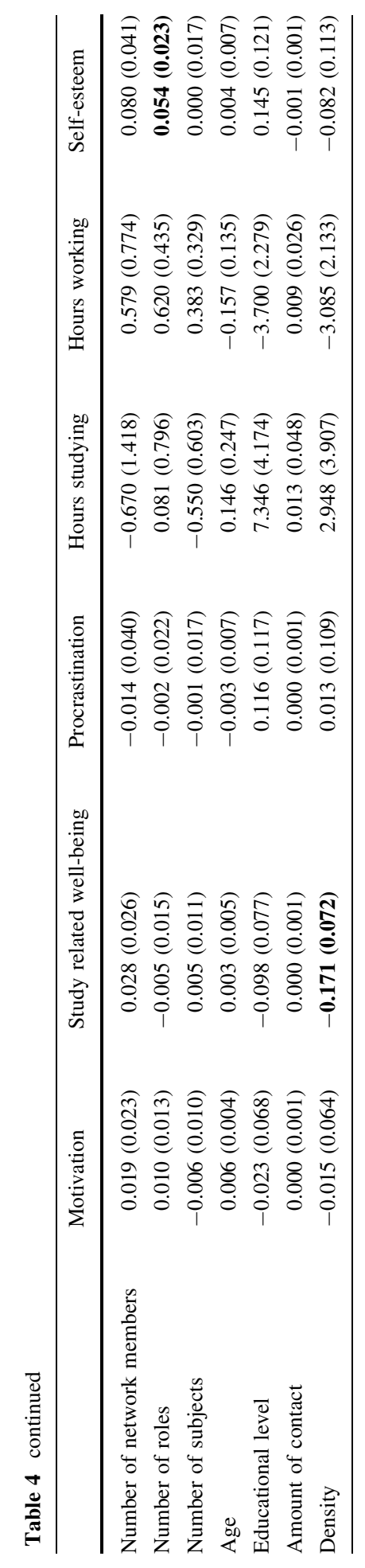


Table 5 Parameter estimates of model 1E

\begin{tabular}{|c|c|c|c|}
\hline & No diploma & Delayed & Accelerated \\
\hline Intercept & $-18.604(5.349)$ & $-5.469(6.039)$ & $-2.861(5.554)$ \\
\hline Gender & $0.595(0.410)$ & $0.125(0.412)$ & $0.493(0.409)$ \\
\hline Beta & $0.552(0.400)$ & $0.745(0.427)$ & $0.536(0.418)$ \\
\hline Gamma & $-0.413(0.377)$ & $-0.416(0.428)$ & $-0.431(0.392)$ \\
\hline Level of secondary education & $-0.856(1.272)$ & $-1.007(1.483)$ & $-1.260(1.328)$ \\
\hline Recommended track & $0.089(0.168)$ & $0.324(0.195)$ & $0.024(0.169)$ \\
\hline SES & $-0.083(0.138)$ & $-0.019(0.152)$ & $0.026(0.143)$ \\
\hline Entry test & $0.011(0.034)$ & $0.032(0.038)$ & $-0.008(0.034)$ \\
\hline Dutch language & $0.048(1.141)$ & $0.857(1.172)$ & 0.745 (1.119) \\
\hline Mathematics & $-1.452(2.305)$ & $-1.163(2.349)$ & $-3.526(2.468)$ \\
\hline Entry age & $0.861(0.202)$ & $-0.068(0.246)$ & $0.251(0.217)$ \\
\hline Companionship partner & $-16.115(0.316)$ & $-3.185(1.561)$ & $-0.183(1.512)$ \\
\hline Companionship parents & $0.912(0.575)$ & $0.189(0.622)$ & $-0.076(0.534)$ \\
\hline Companionship peers & $-0.465(0.661)$ & $-0.994(0.713)$ & $-0.654(0.707)$ \\
\hline Companionship family & $0.122(0.797)$ & $0.705(1.062)$ & $1.314(1.076)$ \\
\hline Emotional support partner & $16.052(0.000)$ & $-1.072(1.573)$ & $0.131(1.516)$ \\
\hline Emotional support parents & $-0.747(0.848)$ & $-0.715(0.887)$ & $-0.301(0.808)$ \\
\hline Emotional support peers & $0.000(0.000)$ & $0.000(0.000)$ & $0.000(0.000)$ \\
\hline Emotional support family & $0.000(0.000)$ & $0.000(0.000)$ & $0.000(0.000)$ \\
\hline Instrumental support partner & $0.006(0.000)$ & $4.449(0.000)$ & $0.316(0.000)$ \\
\hline Instrumental support parents & $1.092(0.822)$ & $0.273(0.866)$ & $1.205(0.811)$ \\
\hline Instrumental support peers & $0.367(0.675)$ & $1.507(0.791)$ & $0.537(0.734)$ \\
\hline Instrumental support family & $-0.133(0.751)$ & $-1.460(1.016)$ & $-1.348(1.046)$ \\
\hline Number of women & $-0.126(0.156)$ & $0.084(0.159)$ & $0.026(0.155)$ \\
\hline Number of network members & $-0.157(0.204)$ & $-0.560(0.207)$ & $-0.106(0.216)$ \\
\hline Number of roles & $0.025(0.115)$ & $0.092(0.115)$ & $0.050(0.118)$ \\
\hline Number of subjects & $0.059(0.084)$ & $0.078(0.089)$ & $0.098(0.087)$ \\
\hline Age & $0.005(0.038)$ & $0.126(0.037)$ & $0.002(0.038)$ \\
\hline Educational level & $1.243(0.602)$ & $0.509(0.628)$ & $0.089(0.624)$ \\
\hline Amount of contact & $0.001(0.007)$ & $-0.008(0.008)$ & $0.001(0.006)$ \\
\hline Density & $-0.279(0.549)$ & $0.138(0.568)$ & $-1.018(0.583)$ \\
\hline Achievement motivation & $-0.340(0.508)$ & $-0.699(0.546)$ & $-0.035(0.526)$ \\
\hline Study related well-being & $0.194(0.408)$ & $-0.357(0.427)$ & $0.156(0.446)$ \\
\hline Procrastination & $0.075(0.292)$ & $0.256(0.306)$ & $-0.881(0.341)$ \\
\hline Hours spent studying & $-0.015(0.010)$ & $-0.004(0.011)$ & $0.004(0.011)$ \\
\hline Hours spent working & $0.033(0.016)$ & $0.020(0.017)$ & $0.000(0.018)$ \\
\hline Self-esteem & $-0.054(0.180)$ & $0.059(0.194)$ & $-0.174(0.179)$ \\
\hline
\end{tabular}

\section{References}

Archer, J., Cantwell, R., \& Bourke, S. (1999). Coping at university: An examination of achievement, motivation, self-regulation, confidence, and method of entry. Higher Education Research \& Development, 18, 31. 
Beck, B., Koons, S., \& Milgrim, D. (2001). Correlates and consequences of behavioral procrastination: The effects of academic procrastination, self-consciousness, self-esteem and self-handicapping. Journal of Social Behavior \& Personality, 16, 3-13.

Berkman, L. F. (1984). Assessing the physical health effects of social networks and social support. Annual Review of Public Health, 5, 413-432.

Berndt, T. J., \& Keefe, K. (1995). Friends' influence on adolescents' adjustment to school. Child Development, 66, 1312-1329.

Berndt, T. J., Laychak, A. E., \& Park, K. (1990). Friends' influence on adolescents' academic achievement motivation: An experimental study. Journal of Educational Psychology, 82, 664-670.

Brisette, I., Cohen, S., \& Seeman, T. E. (2000). Measuring social integration and social networks. In S. Cohen, L. G. Underwood, \& B. H. Gottlieb (Eds.), Social support measurement and intervention (pp. 53-85). New York: Oxford University Press.

Brownlow, S., \& Reasinger, R. D. (2001). Putting off until tomorrow what is better done today: Academic procrastination as a function of motivation toward college work. Journal of Social Behavior \& Personality, 16, 15-34.

Bruinsma, M. (2003). Effectiveness of higher education. Factors that determine outcomes of university education. Rijksuniversiteit Groningen. Gronings Instituut voor Onderzoek van Onderwijs, Opvoeding en Ontwikkeling.

Cassady, J., \& Johnson, R. (2002). Cognitive test anxiety and academic performance. Contemporary Educational Psychology, 27, 270.

Clifton, R., Perry, R., Stubbs, C., \& Roberts, L. (2004). Faculty environments, psychosocial dispositions, and the academic achievement of college students. Research in Higher Education, 45, 801-828.

Cohen, S., Gottlieb, B. H., \& Underwood, L. G. (2001). Social relationships and health: Challenges for measurement and intervention. Advances in Mind-Body Medicine, 17, 129-143.

Cohen, S., Mermelstein, R., Kamarck, T., \& Hoberman, H. (1985). Measuring the functional components of social support. In I. G.Sarason, \& B. R. Sarason (Eds.), Social support: theory,research and application (pp. 73-94). The Hague, The Netherlands: Martinus Nijhoff.

Curtis, S., \& Shani, N. (2002). The effect of taking paid employment during term-time on students' academic studies. Journal of Further \& Higher Education, 26, 129-138.

Cutrona, C. E., Cole, V., Colangelo, N., Assouline, S. G., \& Russell, D. W. (1994). Perceived parental social support and academic achievement: An attachment theory perspective. Journal of Personality and Social Psychology, 66, 369-378.

Davies, M., \& Kandel, D. B. (1981). Parental and peer influences on adolescents' educational plans: Some further evidence. American Journal of Sociology, 87, 363-387.

Davis, M. H., Morris, M. M., \& Kraus, L. A. (1998). Relationship-specific and global perceptions of social support : associations with well-being and attachment. Journal of Personality and Social Psychology, 74, 468-481.

DeBerard, M. S., Spielmans, G. I., \& Julka, D. C. (2004). Predictors of academic achievement and retention among college freshman:a longitudinal study. College Student Journal, 38, 66-80.

DuBois, D. L., Felner, R. D., Meares, H., \& Krier, M. (1994). Prospective investigation of the effects of socioeconomic disadvantage, life stress, and social support on early adolescent adjustment. Journal of Abnormal Psychology, 103, 511-522.

Dubow, E. F., Tisak, J., Causey, D., Hryshko, A., \& Reid, G. (1991). A two-year longitudinal study of stressful life events, social support, and social problem-solving skills: Contributions to children's behavioral and academic adjustment. Child Development, 62, 583-599.

Eppler, M., Carsen-Plentl, C., \& Harju, B. (2000). Achievement goals, failure attributions, and academic performance in nontraditional and traditional college students. Journal of Social Behavior \& Personality, 15, 353-372.

Faber, A. D., \& Wasserman, S. (2002). Social support and social networks: Synthesis and review. Social Networks and Health, 8, 29-72.

Fritzsche, B., Rapp Young, B., \& Hickson, K. (2003). Individual differences in academic procrastination tendency and writing success. Personality \& Individual Differences, 35, 1549.

Greenberger, E., Chuansheng, C., Dmitrieva, J., \& Farruggia, S. P. (2003). Item-wording and the dimensionality of the Rosenberg Self-Esteem Scale: do they matter?. Personality and Individual Differences, 35, 1241-1254.

Hay, I., \& Ashman, A. F. (2003). The development of adolescents' emotional stability and general selfconcept: The interplay of parents, peers and gender. International Journal of Disability, Development and Education, 50, 77-91.

Hays, R. B., \& Oxley, D. (1986). Social network development and functioning during a life transition. Journal of Personality and Social Psychology, 50, 305-313. 
Hermans, H. J. M. (1980). Prestatie Motivatie Test voor Kinderen. Lisse: Swets \& Zeitlinger.

Hofman, W. H. A., \& Van den Berg, M. N. (2004). Highbrows in University Education. Higher Education in Europe, 29, 509-521.

Jackson, T., Weiss, K., Lundquist, J., \& Hooper, D. (2003). The impact of hope, procrastination, and social activity on academic performance of midwestern college students. Education, 124, 310-320.

Jansen, E. P. W. A. (2004). The influence of the curriculum organization on study progress in higher education. Higher Education, 47, 411-435.

Keefe, K., \& Berndt, T. J. (1996). Relations of friendship quality to self-esteem in early adolescence. Journal of Early Adolescence, 16, 110.

Kennedy, M. G., Felner, R. D., Cauce, A., \& Primavera, J. (1988). Social problem solving and adjustment in adolescence: the influence of moral reasoning level, scoring alternatives, and family climate. Journal of Clinical Child Psychology, 17, 73.

Lakey, B., \& Cohen, S. (2000). Social support theory and measurement. In S. Cohen, L. G. Underwood, \& B. H. Gottlieb (Eds.), Social support measurement and intervention (pp. 29-52). New York: Oxford University Press.

Lane, J., Lane, A. M., \& Kyprianou, A. (2004). Self-efficacy, self-esteem and their impact on academic performance. Social Behavior \& Personality: An International Journal, 32, 247-256.

Levitt, M. J., Guacci-Franco, N., \& Levitt, J. L. (1994). Social support and achievement in childhood and early adolescence: A multicultural study. Journal of Applied Developmental Psychology, 15, 207-222.

Lubbers, M. J. (2004). The social fabric of the classroom. Peer relations in secondary education. Rijksuniversiteit Groningen.

Malecki, C. K., \& Demaray, M. K. (2005). What type of support do they need? Investigating student adjustment as related to emotional, informational, appraisal, and instrumental support. School Psychology Quarterly, 18, 231-252.

McKenzie, K., Gow, K., \& Schweitzer, R. (2004). Exploring first-year academic achievement through structural equation modelling. Higher Education Research \& Development, 23, 95-112.

McKenzie, K., \& Schweitzer, R. (2001). Who succeeds at university? Factors predicting academic performance in first year Australian university students. Higher Education Research \& Development, 20, 21-33.

Murtaugh, P., Burns, L., \& Schuster, J. (1999). Predicting the retention of university students. Research in Higher Education, 40, 355-371.

Pescosolido, B. A., \& Levy, J. A. (2002). The role of social networks in health, illness, disease, healing: The accepting present, the forgotten past, and the dangerous potential for a complacent future. In J. A. Levy, \& B. A. Pescosolido (Eds.), Social Networks and health (pp. 3-28). Oxford: Elsevier Science.

Pustjens, H., Van de Gaer, E., \& Van Damme, J. (2004). Effect of secondary schools on academic choices and on success in higher education. School Effectiveness \& School Improvement, 15, 281-311.

Pychyl, T., Morin, R., \& Salmon, B. (2001). Procrastination and the planning fallacy: An examination of the study habits of university students. Journal of Social Behavior \& Personality, 16, 135-150.

Richardson, J., \& Woodley, A. (2003). Another look at the role of age, gender and subject as predictors of academic attainment in higher education. Studies in Higher Education, 28, 475.

Richman, J. M., Rosenfeld, L. B., \& Bowen, G. L. (1998). Social support for adolescents at risk of school failure. Social Work, 43, 309-323.

Robbins, S. B., Lauver, K., Le, H., Davis, D., Langley, R., \& Carlstrom, A. (2004). Do psychosocial and study skill factors predict college outcomes?: A meta-analysis. Psychological Bulletin, 130, 261-288.

Rosenberg, M. (1965). Society and the adolescent self-image. Princeton, New Jersey: Princeton University Press.

Rothblum, E., Solomon, L., \& Murakami, J. (1986). Affective, cognitive, and behavioral differences between high and low procrastinators. Journal of Counseling Psychology, 33, 387-394.

Ryan, A. M. (2000). Peer groups as a context for the socialization of adolescents' motivation, engagement, and achievement in school. Educational Psychologist, 35, 101-111.

Ryan, A. M. (2001). The peer group as a context for the development of young adolescent motivation and achievement. Child Development, 72, 1135.

Schouwenburg, H. C. (1994). Uitstelgedrag bij studenten. Rijksuniversiteit Groningen.

Smith, J., \& Naylor, R. (2001). Determinants of degree performance in UK universities: A statistical analysis of the 1993 student cohort. Oxford Bulletin of Economics \& Statistics, 63, 29.

Smith, J., \& Naylor, R. (2005). Schooling effects on subsequent university performance: Evidence for the UK university population. Economics of Education Review, 24, 549-562.

Spady, W. (1970). Dropouts from higher education: An interdisciplinary review and synthesis. Interchange. Spady, W. (1971). Dropouts from higher education: Toward an empirical model. Interchange. 
Straits, B. C. (2000). Ego's important discussants or significant people: An experiment in varying the wording of personal network name generators. Social Networks, 22, 123-140.

Szafran, R. (2001). The effect of academic load on success for new college students: Is lighter better?. Research in Higher Education, 42, 27-50.

Tice, D., \& Baumeister, R. (1997). Longitudinal study of procrastination, performance, stress, and health: The costs and benefits of dawdling. Psychological Science, 8, 454-458.

Tinto, V. (1975). Dropout from higher education: A theoretical synthesis of recent research. Review of Educational Research, 45, 89-125.

Van den Berg, M. N. (2002). Studeren? (G)een punt! Een kwantitatieve studie naar studievoortgang in het Nederlandse wetenschappelijk onderwijs in de periode 1996-2000. Erasmus Universiteit Rotterdam.

Van den Berg, M. N., \& Hofman, W. H. A. (2005). Student success in university education: A multimeasurement study of the impact of student and faculty factors on study progress. Higher Education, $50,413-446$

Wall, J., Covell, K., \& Maclintyre, P. D. (1999). Implications of social supports for adolescents' education and career aspirations. Canadian Journal of Behavioural Science, 31, 63-71.

Wentzel, K. R. (1998). Social relationships and motivation in middle school: The role of parents, teachers, and peers. Journal of Educational Psychology, 90, 202-209.

Wentzel, K. R. (1999). Social-motivational processes and interpersonal relationships: Implications for understanding motivation at school. Journal of Educational Psychology, 91, 76-97.

Wentzel, K. R., Barry, C. M., \& Caldwell, K. A. (2004). Friendships in middle school: Influences on motivation and school adjustment. Journal of Educational Psychology, 96, 195-203.

Wesley, J. (1994). Effects of ability, high schools achievement, and procrastinatory behavior on college performance. Educational \& Psychological Measurement, 54, 404.

Zeegers, P. (2004). Student learning in higher education: A path analysis of academic achievement in science. Higher Education Research \& Development, 23, 35-56. 